\title{
A contemporary culture in the context of communicational exchange of informational civilization: specialities and issues
}

\begin{abstract}
The subject of the paper is cultural development on a contemporary social stage in the context of cultural and communicational exchange. The author underlines the role of mass media as one of the factors which form a new structure of the world. They make it by means of systematical, historical, comparative research methods. Also the author determines that every culture is unique and cultural factor dominates in communication. Communications are linked with the peculiarities of ethnic processes, this fact is evident. If cultural differences are increased, they can increase the distance between communicators in the process of intercultural and interethnic interaction. And we have to remember about it as we make a common informational space. Modern culture in its global form is a system of American values, American lifestyle and way of thinking. Mentality, values, traditions, customs are important for every ethnic culture in contrast to global culture that is illusory and based only on scientific and technical progress, full of desire to be adapted for mass audience. An approach to new cultural realities should be determined according to new categories; a culture of every ethnic group should take its rightful place in the family of world cultures. The author makes a conclusion that if we form a common informational space we shouldn't destroy heterogeneous cultural world. And mass media have to propagandize values of tolerance and respect.
\end{abstract}

Keywords: globalization, integration, culture, mass media, communication
Volume 3 Issue 4 - 2019

\section{Evgeniya Kuznetsova \\ The Department of Law and Humanities, University of Management “TISBI”, Russian Federation, Russia}

Correspondence: : Evgeniya Kuznetsova, The Department of Law and Humanities, University of Management “TISBI”, Russian Federation, Russia, Tel +7917864II84,

Email kuznetzova.evgeniya20I2@yandex.ru

Received: June 18, 2019 | Published: July 17, 2019

\section{Introduction}

In the period of globalization culture as a factor of social and historical changes has become again a main topic of research of many scientists. International integration has made cultural system a semantic integrator of many disparate phenomena, many of which enter the world culture by means of radio, television, Internet. World culture has no boundaries. It includes values expressed in ethical principles, in genuine scientific inventions, in unique technological solutions. Spiritual values of world culture are general values. But individual samples of each subject consist of universal values and those values which are determined by local cultural tradition of his people. The loss of one of the components in this case means that moral guidance and spiritual ideals disappear. People living within the boundaries of their specific culture should be oriented also for values which have the status of general ones, even if they do not coincide with the tradition of their culture. Those subjects who prefer only local values limit the possibilities for the development of themselves and their culture, ${ }^{1}$ at the same time forgetfulness of native culture, its repression violate subject's right for cultural and ethnic identity.

Globalization, which has embraced the whole world nowadays and has become an integral part of it, is a product of many processes. The first attention towards this concept was marked in the $19^{\text {th }}$ century at the height of interest towards such topics as geopolitics, imperialism, international financial, industrial organization and the integration of Europe. The term firstly appeared in the databases of the Library of Congress of the United States of America in 1987, later discussions of this kind were resumed in connection with themes of colonialism's end and expansion of industrial civilization into countries of the third world. Then the discussion was continued already in the 90 -ies years because of several reasons.
At first, we mean here the rapid development of informational technologies, Internet, satellite communications, i.e. the beginning of informatization. Secondly, new technologies have expanded labour market and changed its structure. Intensification of population's flows has determined the lifestyle of the developed countries. Thirdly, the changes on the geographical map of the world, the collapse of the Soviet Union and Yugoslavia, the end of the cold war, the collapse of the so-called socialist camp identified the contents of new ideologies and orientations in the world.

\section{Methods}

The role of concept of globalization is to determine these directions and priorities, contradictions between participants in the processes of globalization and integration, and representatives of national political and intellectual elites. We use in our article such research methods as systematical, historical and comparative which allow to draw conclusions about the peculiarities of the development of the informational space on different stages of its formation according to conceptions of various Russian and foreign researchers. The concepts of M. Mcluhan, D. Bell, R. Williams, F. Fukuyama, G. Pocheptsov, A. Toffler are based on different accents in the context of formation of informational space. But systematic approach allows us to select next idea, which is common to all researchers.

\section{Results}

A contemporary world is based on global informational network (Internet). One of the main materials in new civilization is information. Many phenomena and processes occur primarily because of cultural and communicative processes. On the stage of world's transformation into the civilization of the Third Wave mass 
media play the key role, the information itself acts as a stimulator of creative forces and searches. Constant participation in communicative exchange teaches people to navigate in global flows of information, regardless of existing standards and prejudices. Thanks to information and mass media civilization begins to rebuild education, define the boundaries of scientific research and reorganize mass media. Media is certainly one of the most important factors in the unfolding process of globalization. It is from one hand. On the other hand, recent years are characterized by internal regional differentiation of national states, associated with the principles of social reconstruction and manifestation of ethnic and cultural differences. In particular, it is represented in the expansion of medial networks at the regional level (the appearance of various publications, press, regional broadcast television stations and specialized television channels). One of the researchers in the field of mass media R. Williams states that the emergence of contemporary models of media, actualized in the era of "informational society", should be attributed to the social manifestation of era of industrialization and urbanization. We observe how a role of a subject as a participant of globalization arises, and at the same time his desire to create his own world also arises. $\mathrm{R}$. Williams highlights this phenomenon in a special way and believes that we deal with an experience of a new type.

According to some researchers, television acts as a determining factor in forming of a cultural space of postindustrial (informational, transindustrial) civilization. A famous sociologist and founder of the theory of postindustrial society D. Bell writes: "For the first time in history, television has created a phenomenon that the ancient Greeks call "heaven" or that M. Mcluhan determines as "global village". ${ }^{2}$ Nowadays we deal with different directions, tendencies and various approaches in the study of television, in particular, and mass media, as a whole. It should be noted that research traditions of different terminologies exist in this area. We use such terms as mass media, mass communication, etc. In common terminology the word "communication" means the process of converting data into knowledge marks, and the word "communications" indicates symbols which give meaning to our everyday life. But we mean here the existence of different sign systems. The term "mass media" is widespread and common. Any means of communication that transmits or communicates some information is medium. Telephones, cinema, TV are media. ${ }^{3}$ At the same time, the connection of a medium with its manifestation and area of existence is carried out differently, it depends on the degree of "purity" of each medium. So, printed media is a form of mediation. Electronic media in a certain way are associated with their area of existence or broadcasting and form their own universe. In the $19^{\text {th }}$ century printed media have become one of the major factors in the development of society, and electronic media since its inception have been linked with a social context.

In the context of the theory of R. Williams the connection between the character of society and communicational technologies is investigated, and the history of this connection goes back into the $19^{\text {th }}$ century, into the period of railroads and telegraph. "Mass communications should not be confused with their makers. Nature of audience, communications and communicators demonstrate themselves differently. It's a specification of mass communications. ${ }^{4}$ In informational society a manifestation of any medial phenomenon occurs in the midst of complex cultural situations where social and cultural processes are closely linked, they fill technological phenomena in cultural meanings. This question arises in recent years because of the unprecedented growth of informational technologies.
It complicates the prediction of social and cultural changes in this particular area and in the whole cultural sphere. In the 90-ies years of the $\mathrm{XX}^{\text {th }}$ century a new phase in the development of world and domestic mass communications comes, and within this period, the processes occurring in the domestic media practically coincide with similar processes in European and in the world's media. According to many researchers the main features of the situation in the global medial space of the end of the last century are unpredictability and unprecedented speed of technological innovations. They do not allow us to make any predictions about the consumption of products in the twenty-first century and don't allow to doubt in their cultural significance and connection with informational technologies and dependence on them.

In the twenty-first century, the dominant media of communication are electronic media. ${ }^{1}$ The main features of new medial culture are spread of Internet and cable television, and a great number of channels which give the viewer a wide choice. But here we deal with such a phenomenon as zapping. It is a permanent switching of channels creating the effect of simultaneous viewing of a wide range of different programmes. We can make a conclusion that a modern consumer of television products isn't able to perceive any semantic integrity of the content, but at the same time he forms the consciousness of some fragments which create fragmented collage of cultural experience. Video is rather popular because it can be easily removed if a viewer doesn't need it. As a result, video and television become a kind of digest. As we can see, the proliferation of cable and satellite TV channels is one more step towards the freedom of the viewer from the "tyranny" of software developers. A rapid proliferation of channels has completely changed the image of television and culture. At the same time it fascinates both researchers and people who will have to be adapted towards new technologies. "At the end of the twentieth century in Europe and in the United States of America a new electronic superhighway in 500 channels occurred. It's a universe of unlimited interactivity and the possibility of consumer's control. This is future of promise and choice, ${ }^{5}$ but not all researchers are so optimistic, and predictions in this area are very contradictory. We'll analyze the point of view of one famous American futurologist A. Toffler. ${ }^{6}$

According to him one of the main features of the informational society is also unpredictability. Changes are completely unpredictable, they go into different directions, they become the main feature of the life of mankind of the Third Wave's civilization. They determine society's and individual's destinies. And these changes are expressed in the explication of mass media. So forecasting of future social image is corresponded with the development of mass media from the technological and socio-cultural point of view. ${ }^{7}$ Social ethnic component is closely connected with the operation of modern communicative community. G. Pocheptsov states that process of collecting, processing and storage of information is ethnically significant for any science. G. Pocheptsov writes that the flow of information is nationally specific. It is impossible to make an effective communication without taking into account this fact. It is important to combine external and internal features of this national specificity. External factors reflect the data communication channel, key communicators. Internal factors are related with the content of the selection of priority subjects, ${ }^{8}$ In modern conditions the process of communication has a big influence on individual's activities and the functioning of society on a whole. Formation of public structures and public opinion occurs by means of improved communications, through their critical perception and comprehension. 


\section{Discussion}

Communication is a part of the process of globalization It is impossible to explain integration, if we don't carefully look at the communicative process and its components. Trade, migration, exchanges of tourists between different countries form a communicative network in the world. However, communication is impossible without mutual understanding between different people. Communications are connected with the peculiarities of ethnic processes, this fact is evident. If cultural differences are increased, they can increase the distance between communicators in the process of intercultural and interethnic interaction. This issue is investigated by researchers from different positions. S.V. Orlov calls street-art, music, technology among all important indicators of cultural and communicative practices, ${ }^{9}$ The cultural factor is definitely important in communication. A subject identifies himself with some ethnic and cultural group and defines his attitude towards his roots. We always identify ourselves with some place and time. At the same time we enter an interaction with other individuals, representatives of other peoples and other cultural medial samples. There is no key to the establishment of warm relations within the communication of one ethnic group, there is no standardized way to form such relations in intercultural interaction. But in these entire cases cultural factor plays a dominant role. Cultural mosaic significantly modifies the structure of the unity of the world. ${ }^{10}$

Formation and development of new media have substantially changed the essence and the content of communicative process. Mass media create a new virtual reality often substituting a true one, create a new culture aiming to replace any ethnical culture. Mass culture is a planetary phenomenon caused by the growth of high technologies and informational space. But still it would be a mistake to equate mass culture based on the intercultural integration and globalization on the basis of stereotyped patterns. That's why in the second half of the 20th century a trend of cultural differentiation disappears. Not only respect for other cultural traditions and values, but also the awareness of own traditions and values should be a condition for the further development of intercultural communication and intercultural dialogue. And contemporary popular culture in its global version is a cultural system, lifestyle and way of thinking of western technological model. Each ethnic identity has its own mentality, values, traditions, customs, in contrast to mass culture, elusive, and based on technological progress, and on the desire to please an audience. ${ }^{11}$

\section{Conclusions}

So, a contemporary culture of the informational society is characterized by priority of visual over verbal, priority of mosaic forms, bright, attractive shell over the content, dominance of consumer's desire to buy anything. New media change the existence of culture itself. "The Media is the message" means "the tool itself is a message." A modern approach to cultural realities should be determined according to new categories, and each culture wants to take its own, special place in the community of world cultures. M. Castells examines the concept of "popular culture" in the context of the informational society. ${ }^{12}$ It continues to exist, but in a different form. According to M. Castells cultural industry has no common sense. It's the first point. Secondly, its forms are standardized, implemented, they depend on the product itself. Thirdly, popular culture plays the role of psychological protection for people because human psychic needs a kind of relaxation and rest.
We associate mass culture with medial culture, and there is no doubt that mass media have a decisive influence on modern culture, fashion and life styles. And television occupies here a leading position among all other forms of mass media. "Television is a form of the popular culture of the end of the $20^{\text {th }}$ century. It is the most common form of spending free time in the world". ${ }^{13}$ If printed media is a means of informational and semantic exchange between two or more actors, telecommunications is a means of informational and semantic exchange at a distance between many different actors. The phenomenon of mass culture continues to exist in the informational society in industry of entertainment, as well as in the areas connected with standardized processes. A common space of the world is a common informational space of cultures. A condition for the personal development of social groups and communities is cultural pluralism. But today in our society mass media continue to be a threat for the existence of many cultures. Promotion of intolerance, rejection of values of other peoples becomes a prerequisite for fomenting of ethnic conflicts. ${ }^{14}$ Meanwhile, the establishment of a new world order should not lead to cultural homogeneity of society blurring its cultural diversity. In the context of a new world order's formation we should talk about strengthening of our attention to such values as mutual respect and disparagement of material enrichment. And mass media should act in this case as a source of propaganda of the values of this kind.

\section{Funding details}

None.

\section{Acknowledgments}

None.

\section{Conflicts of interest}

The author declares that there are no conflicts of interest.

\section{References}

1. Kuznetsova EV. The problem of cultural and communicative processes' development on the stage of informational civilization. New ideas in philosophy, Russian Federation. 2016;294-298.

2. Bell D. The Coming of Post-industrial Society. Science, Russian Federation. 1999;110-210.

3. Shepinskaya NE. Television as a form of culture. Russian Federation $2005 ; 12-125$.

4. Williams R. Television. Germany. 1992;12-285.

5. Wright Ch. Mass Communication. A Sociological Perspective, USA. $1988 ; 10-235$.

6. Toffler A. Future Shock. Russian Federation. 2001;240-558.

7. Toffler A. The Third Wave. USA. 1980;120-526.

8. Pocheptsov GG. Psychological wars. Russian Federation. 2000;90-320.

9. Orlov SV. Informational society as a complex problem. Perm University Herald, Russian Federation. 2015;4(24);5-15.

10. Narochinskaya EA. National conflicts and Their Resolution. Russian Federation. 2000;130-270.

11. Kuznetsova E, Goryacheva O, Patenko G. Phenomenon of Mass Culture Problems and Controversies. Mediterranean Journal of Social Sciences, Bulgaria. 2015;3:296-302. 
12. Kastels M. Information economics, society and culture. Russian Federation. 20001;305-420.

13. Price ME. Television. The Public Sphere and the National Identity, UK $1995 ; 85-320$.
14. Levin K. Resolution of Social Conflicts. Russian Federation. $2000 ; 130-258$. 